This article was downloaded by: [De Cruz, Helen]

On: 2 September 2008

Access details: Access Details: [subscription number 902116740]

Publisher Routledge

Informa Ltd Registered in England and Wales Registered Number: 1072954 Registered office: Mortimer House, 37-41 Mortimer Street, London W1T 3JH, UK

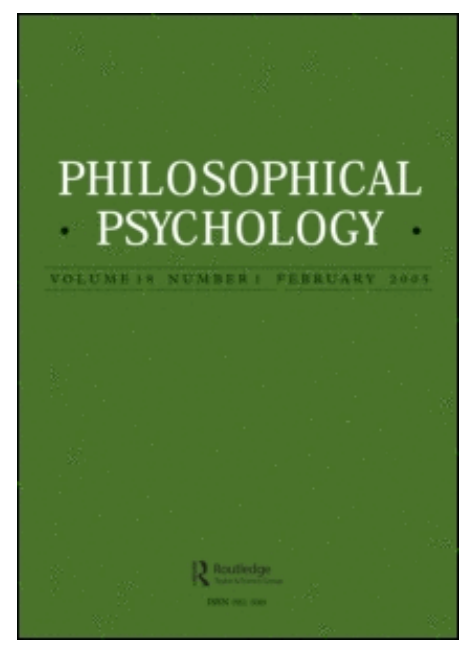

Philosophical Psychology

Publication details, including instructions for authors and subscription information:

http://www.informaworld.com/smpp/title content=t713441835

\title{
Knowledge of Number and Knowledge of Language: Number as a Test Case for the Role of Language in Cognition \\ Helen De Cruz; Pierre Pica
}

Online Publication Date: 01 August 2008

To cite this Article De Cruz, Helen and Pica, Pierre(2008)'Knowledge of Number and Knowledge of Language: Number as a Test Case for the Role of Language in Cognition',Philosophical Psychology,21:4,437 - 441

To link to this Article: DOI: $10.1080 / 09515080802284217$

URL: http://dx.doi.org/10.1080/09515080802284217

\section{PLEASE SCROLL DOWN FOR ARTICLE}

Full terms and conditions of use: http://www.informaworld.com/terms-and-conditions-of-access.pdf

This article may be used for research, teaching and private study purposes. Any substantial or systematic reproduction, re-distribution, re-selling, loan or sub-licensing, systematic supply or distribution in any form to anyone is expressly forbidden.

The publisher does not give any warranty express or implied or make any representation that the contents will be complete or accurate or up to date. The accuracy of any instructions, formulae and drug doses should be independently verified with primary sources. The publisher shall not be liable for any loss, actions, claims, proceedings, demand or costs or damages whatsoever or howsoever caused arising directly or indirectly in connection with or arising out of the use of this material. 


\section{Knowledge of Number and Knowledge of Language: Number as a Test Case for the Role of Language in Cognition}

\section{Helen De Cruz and Pierre Pica}

The relationship between language and conceptual thought is an unresolved problem in both philosophy and psychology. It remains unclear whether linguistic structure plays a role in our cognitive processes. This special issue brings together cognitive scientists and philosophers to focus on the role of language in numerical cognition: because of their universality and variability across languages, number words can serve as a fruitful test case to investigate claims of linguistic relativism.

Keywords: Linguistic Relativism; Natural Language; Natural Numbers; Number Vocabulary; Numerical Cognition

The question as to how language and thought are related is an ancient and unresolved problem in both philosophy and psychology. Language might shape thought in the trivial sense that it enables us to share information, but it remains unclear whether linguistic structure as such actually plays a role in our cognitive processes, either by structuring cognitive tasks through inner speech or by ordering the world around us through lexical and syntactic tools. The common sense view on this issue, and one adopted by many philosophers (e.g., Clark, 2006; Carruthers, 1996; Fodor \& Pylyshyn, 1988), is that natural language does play a crucial role in mediating human cognitive processes; it is what makes human cognition unlike that

Helen De Cruz is a Postdoctoral Fellow in the Centre for Logic and Analytical Philosophy at the University of Leuven. Pierre Pica is 'chargé de recherche' at the Centre National de la Recherche Scientifique (National Center for Scientific Research).

Correspondence to: Helen De Cruz, Centre for Logic and Analytical Philosophy, University of Leuven, Kardinaal Mercierplein 2, 3000 Leuven, Belgium. Email: helen.decruz@hiw.kuleuven.be 
of other animals. But this common sense view is increasingly challenged by cognitive scientists, who have experimentally demonstrated that prelinguistic infants, nonhuman animals and patients with seriously impaired linguistic skills are capable of rich and abstract thought. Consequently, some psychologists (e.g., Bloom, 2002) now favor the position first voiced by Augustine of Hippo that conceptual thought is independent of language; the latter merely acts as a tool to label preexisting ideas or to acquire the ideas of others. Others such as Chomsky (2000) advocate that the conceptual/intentional system is universal but that performance differences might account for the observed variation.

Since natural languages differ in their structure, one way to attempt to resolve the debate is to investigate whether speakers of different natural languages conceptualize the world differently. The strongest variant of linguistic relativism, the claim that speaking a particular natural language influences cognition, is somewhat misleadingly termed the Whorfian hypothesis. Whereas the linguist Benjamin Whorf (1956) focused almost exclusively on the influence of language on thought in general, empirical research on linguistic relativity today is characterized by more experimentally controlled domain-centered approaches (see Pinker, 2007, for a recent discussion). These studies look at a domain of perceived reality, such as number and space and investigate how various languages encode it.

In recent years, the representation of number has emerged as a fruitful test case for the role of language in cognition. The neural underpinnings and phylogenetic origins of number are well understood in comparison with many other domains of conceptual knowledge. Since humans share the ability to discriminate numerosities with a wide variety of other species, we can expect that number is a relevant semantic domain across cultures. In fact, a large body of linguistic data shows that there are no known languages that completely lack number words, although there is considerable variation in their complexity. Languages range from having completely regular positional numeral systems, such as the Arabic numerals, to Amazonian and Australian languages that only possess a few number words (Hurford, 1987; Ifrah, $1985)$. While it is now generally established that certain elementary numerical skills such as estimation and calculations with small numbers $(n<4)$ are present in infants and nonhuman animals, it still remains to be investigated whether language is essential for the development of more advanced numerical competences, such as representing larger natural numbers, counting, or arithmetic, and whether both abilities belong to the same domain of knowledge.

Despite intensive training, to date no nonhuman animal has mastered the open-ended, precise quantificational skills with larger numbers that is characteristic of integer-counting lists. The fact that both natural language and natural numbers are uniquely human suggests a link between the two, leading several developmental and comparative psychologists to propose that language enables us to go beyond the limitations of our innate numerical capacities. Carey (2004) argues that number words help young children to individuate numerosities precisely, something that they are not able to do with their intuitive approximate numerical skills. Hauser, Chomsky and Fitch (2002) suggest that the ability to make recursive and 
open-ended structures, which they believe to lie at the basis of language, enables us to formulate open-ended counting systems. For Spelke (2003), the compositional character of the language faculty (an idea related to one advanced by von Humboldt, $1836 / 1999$ ) allows us to flexibly combine the hitherto isolated domain-specific core knowledge domains: in the case of number, natural language can combine the small, precise capacity for subitizing small numerosities up to three or four and the larger approximate system. This last view seems compelling, given that neuropsychological and experimental data indeed support a fine-grained modularity for elementary numerical skills. On the other hand, some studies with aphasic patients (e.g., Varley, Klessinger, Romanowski, \& Siegal, 2005) and children with specific language impairments (Donlan, Cowan, Newton, \& Lloyd, 2007) seem to suggest that reasoning about and manipulating natural numbers, especially arabic digits, do not require language. Thus the role of language in the development of numerical cognition remains unresolved.

The issue of the role of language in numerical cognition is further complicated by the fact that the concept of number appears to be less clear-cut than philosophers and psychologists generally believe. Even within one culture, different numerical representations-elementary, object-specific and complex, abstract-can be used alongside each other, as was recently illustrated for Melanesian and Polynesian languages (Beller \& Bender, 2008). Indeed, as the diversity of the contributions for this special issue show, numerical cognition can be decomposed into various more elementary skills, such as one-to-one correspondence, symbolic representation, and estimation. In recent years, experimental studies have examined whether speakers of different languages encode numerosities differently. Especially studies of cultures with extremely limited number vocabularies (e.g., Pica, Lemer, Izard, \& Dehaene, 2004) could be informative, because they provide us with the rare opportunity to study how a diminished number vocabulary affects cognition in neurologically healthy subjects.

This special issue brings together for the first time cognitive scientists and philosophers from a wide diversity of disciplines (psychology, linguistics, education, neuroscience, analytic philosophy and philosophy of mind) to focus on the role of language in numerical cognition. One group of papers examines linguistic relativity from the broad perspective of how speaking any natural language at all may influence cognition. Butterworth and Reeve present their experiment involving classical methods of developmental psychology that indicates that two groups of monolingual Australian Aboriginal children with a limited number vocabulary (Warlpiri and Anindilyakwa) possess similar numerical concepts, compared to those of a control group of Aboriginal children who only spoke English. Decock poses the problem that both the successor function and Hume's principle (equinumerosity) can play a role in number concept acquisition and that this further complicates the question of the role of language in numerical cognition. De Cruz argues for an extended mind perspective on numerical representation. Although language is only one among several external media to represent natural numbers, it may be impossible to represent natural numbers without the help of any external media. 
Three papers will examine how speaking one or more particular natural languages can influence conceptual thought, an approach traditionally associated with linguistic relativism. Izard, Pica, Spelke, and Dehaene discuss their experimental psychological research on the emergence of exact equality as a prerequisite for conceiving exact numbers, by focusing on the development of this concept in speakers of Mundurucu (who have a very limited number vocabulary) and two-anda-half-year-old Western children. Pica and Lecomte present a linguistic analysis of Mundurucu number words to examine possible effects of their linguistic limitations on numerical cognition. Dowker, Bala, and Lloyd examine the claim that the regularity of counting systems is a major factor in early numerical competence. They show that children who speak languages with regular number word systems (Welsh and Tamil) exhibit an advanced numerical competence compared to children who speak languages with irregular counting systems (e.g., English).

A third group of papers will investigate whether using language in a particular way influences cognition. With their background in neural network modeling, Verguts and Fias provide a conceptual framework to understand the often diverging results in numerical tasks, showing what neural differences might underlie symbolic versus nonsymbolic numerical representation. Vlassis' study in educational psychology indicates that children's understanding of abstract numerical concepts, such as negative numbers, correlates with their ability to manipulate the symbols that represent these entities. In keeping with Vygotsky's bootstrapping approach, her analysis suggests a strong relationship between communicational tools, such as language and symbols, and cognitive development.

\section{References}

Beller, S., \& Bender, A. (2008). The limits of counting: Numerical cognition between evolution and culture. Science, 319(5860), 213-215.

Bloom, P. (2002). Mindreading, communication, and the learning of names for things. Mind \& Language, 7, 37-54.

Carey, S. (2004). Bootstrapping and the origin of concepts. Daedalus, 133, 59-68.

Carruthers, P. (1996). Language, thought, and consciousness. Cambridge: Cambridge University Press.

Chomsky, N. (2000). The architecture of language. New Delhi: Oxford University Press.

Clark, A. (2006). Material symbols. Philosophical Psychology, 19, 291-307.

Donlan, C., Cowan, R., Newton, E. J., \& Lloyd, D. (2007). The role of language in mathematical development: Evidence from children with specific language impairments. Cognition, 103, 23-33.

Fodor, J., \& Pylyshyn, Z. (1988). Connectionism and cognitive architecture: A critical analysis. In S. Pinker \& J. Mehler (Eds.), Connections and symbols (pp. 309-330). Cambridge, MA: MIT Press.

Hauser, M. D., Chomsky, N., \& Fitch, W. E. (2002). The faculty of language: What is it, who has it, and how did it evolve? Science, 298(5598), 1569-1579.

Hurford, J. R. (1987). Language and number: The emergence of a cognitive system. Oxford: Oxford University Press.

Ifrah, G. (1985). From one to zero: A universal history of numbers. New York: Viking. 
Pica, P., Lemer, C., Izard, V., \& Dehaene, S. (2004). Exact and approximate arithmetic in an Amazonian indigene group. Science, 306(5695), 499-503.

Pinker, S. (2007). The stuff of thought: Language as a window into human nature. New York: Viking. Spelke, E. (2003). What makes us smart? Core knowledge and natural language. In D. Gentner \& S. Goldin-Meadow (Eds.), Language in mind: Advances in the study of language and thought (pp. 277-311). Cambridge, MA: MIT Press.

Varley, R. A., Klessinger, N. J. C., Romanowski, C. A. J., \& Siegal, M. (2005). Agrammatic but numerate. Proceedings of the National Academy of Sciences of the United States of America, 102, 3519-3524.

Von Humboldt, W. (1999). In M. Losonsky (Ed.), On language: On the diversity of human language construction and its influence on the mental development of the human species (2nd. rev. ed.). New York: Cambridge University Press, (Original work published in 1836).

Whorf, B. L. (1956). In J. B. Carroll (Ed.), Language, thought and reality: Selected writings of Benjamin Lee Whorf (pp. 134-159). Cambridge, MA: MIT Press. 